\title{
Editorial
}

\section{Restoration and the Reentry of Nature}

On the inside of the front cover of the winter issue of R\&MN we included a short quote from Loren Eiseley's 1970 book, The Invisible Pyramid, in which he discusses the problem of the relationship between our species and the rest of nature. Basically, he is saying that the problem is a complex one because our species, though a product of nature, has in some sense gone beyond nature, transcending what Eiseley calls the "first world" of nature itself to create what he calls a "second world," the world of artificial things.

Though obviously an "environmentalist," Eiseley shows little interest in abandoning the second world. Instead, he suggests that what is needed is a "third world," which "combines elements of the original two ..." and provides a way of reentering nature without giving up the "knowledge gained on the pathway to the moon."

What we need, in other words, is a way of living in the world without doing violence either to our own nature, or to the rest of nature.

The question, which Eiseley leaves unanswered, is, how do we do this?

That, of course, is a question that leads directly into philosophical deeps with which we are no more prepared to contend that Eiseley was. At the same time, it is interesting to consider it from a more or less practical point of view.

Assuming that one wishes to do so, how does one actually reenter nature?

There really are quite a few more or less popular ways of doing this. Some of the most obvious are hiking, backpacking, canoeing, mountain climbing, and the like.

Then there are hunting and fishing. There is the gathering of wild plants for food, dye-making and so forth in the manner popularized by the late Euell Gibbons. And there is plain nature study, ranging from birding and plant identification all the way to field research in ecology and its various branches.

Gardening, and agriculture generally, is a prime candidate, celebrated by writers since ancient times as a way of getting back in touch with nature. Recent writers such as René Dubos and Frederick Turner, the University of Texas-Dallas cultural historian, have written of gardening as a model for a healthy relationship with nature.

But there are problems here. The first problem is that all these activities bring us into nature either as a visitor (hiking, for example), or, as in the case of agriculture, they involve some degree of exploitation, or arbitrary rearrangement of nature. They bring us into contact with nature, but not into full participation in it. Hunting and the gathering of wild plants for food are a possible exception, but these lead us to another problem: each of these activities is a highly specialized kind of activity. Each implies a distinctive state of mind or attitude toward nature, and so has its distinctive value. But none offers complete immersion in nature through the exercise of the full range of our abilities as human beings, makers-and inhabitants-of Eiseley's second and third worlds.

It seems to me that restoration does this. I have pointed out elsewhere (R\&MN 1:3) that restoration is a form of agriculture. Only recently, watching a group of people collecting seed on Curtis Prairie, did I realize that restoration really takes us back much further than that, to the time of hunting and gathering, and the kind of unselfconscious, direct economic relationship with nature that way of living implies.

And of course, restoration also brings us up to the science of ecology, and all sorts of complex, more or less abstract problems about the nature of things considered in scientific terms.

So I see restoration as recapitulating the entire history of our species and its evolving relationship with nature. And this, I think, makes it a most interesting example of the sort of thing Eiseley was looking for-a model for a healthy relationship with nature-and, more than that, a ritual of reentry, an act that really dramatizes and carries us through the phases of a rich, participatory-which is to say both respectful and manipulative-relationship with nature.

I can think of nothing else that does this quite so clearly. It is something like this, I think, far more than hunting or gardening or ecology or preservation alone that holds the promise of enabling us to reenter the world and to recover it, not just as a place, or even as an "environment," but as a habitat for human beings.

We would like to note that, with this issue, $\mathbf{R} \& \mathbf{M N}$ completes its first five years of publication. Five years is not a major anniversary, perhaps, but it is one that lots of new publications never do reach. We mark it with some pride and a great deal of gratitude to our readers and contributors.

William R. Jordan III 